\title{
Establishment of a Qualified Integrated Care System After Total Knee Arthroplasty as a Role of Regional Rheumatoid and Degenerative Arthritis Centers
}

\section{Eun Young Han}

Jeju National University College of Medicine, Regional Rheumatoid and Degenerative Arthritis Center, Jeju National University Hospital

\section{Sang Rim Kim}

Jeju National University College of Medicine, Regional Rheumatoid and Degenerative Arthritis Center, Jeju National University Hospital

Sang Hee ( $\sim$ ISH2018@yuhs.ac)

Severance Hospital, Yonsei University College of Medicine

\section{Research Article}

Keywords: Athroplasty, Knee, Ostearthritis, Rehabilitation, Aged

Posted Date: July 6th, 2021

DOl: https://doi.org/10.21203/rs.3.rs-656779/v1

License: (9) (1) This work is licensed under a Creative Commons Attribution 4.0 International License. Read Full License 


\section{Abstract}

Background: The geriatric population and advanced knee osteoarthritis are rapidly increasing in Korea, and the socioeconomic burden of total knee arthroplasty (TKA) is increasing. This study aimed to analyze the demographic, clinical and socioeconomic characteristics of patients who underwent TKA and to differentiate the factors affecting participation in inpatient-intensive rehabilitation programs after TKA in oo regional rheumatoid and degenerative arthritis centers established by the government.

Methods: This retrospective cohort study included 845 patients ( 735 females; $72.0 \pm 5.8$ years) diagnosed with primary osteoarthritis $(\mathrm{OA})$ of the knee who underwent elective unilateral primary TKA between January 2013 and June 2016. Demographic, clinical and socioeconomic characteristics, including age, body mass index, obesity, length of stay, OA severity, underlying disease, education level, occupation, and location of residence, were reviewed. Patients were allocated to the TKA-only group (home discharge) and to the TKA+ rehab group (participation in post-TKA rehabilitation). The variables were analyzed and compared before and after the establishment of the center and according to participation in intensive rehabilitation.

Results: They showed a predominance of females and geriatrics and a high prevalence of comorbidities and obesity. Additionally, the only factor differentiating participation in intensive rehabilitation was the location of residence.

Conclusion: The regional rheumatoid and degenerative arthritis center was appropriate to meet the high need for participating in intensive rehabilitation after TKA and for the qualified integrated post-TKA care system. Policy support should ensure early rehabilitation and a qualified integrated care system and prepare for the increased burden of revision, and future longitudinal studies should be conducted to assess the long-term effect of the integrated post-TKA rehabilitation program on functional outcomes and patient survivorship free from revision.

\section{Introduction}

The geriatric population is rapidly growing in South Korea, and osteoarthritis (OA) is one of the most common degenerative bone and joint diseases in geriatrics, and the knee is most commonly involved. Patients with knee OA complain of severe pain that causes gait disturbance and frailty.[1] Total knee arthroplasty (TKA) is an effective method for treating advanced knee arthritis[2], and primary and revision TKAs have tremendously increased from 2001 to 2010 by $407 \%$ and $267 \%$, respectively.[3] The socioeconomic burden of TKA is also increased in Korea, and TKA is the 6th most common surgical procedure in Korea. In terms of overall cost, it is the fourth highest, and the days of hospitalization per surgery case was longest in 2018.[4] Although the National Health Insurance (NHI) system and Health Insurance Review and Assessment Service (HIRA) provide universal coverage in Korea, most patients should pay out-of-pocket (OOP) for health care, which accounts for approximately $32-26 \%$ of annual total household health care spending[5] and may cause an inequality of access to medical services 
among socioeconomic groups and geographic and overconcentration of medical resources and health care utilization of patients in metropolitan areas. Thus, the Ministry of Health and Welfare established and has been operating five regional rheumatoid and degenerative arthritis centers to promote decentralization of medical resource utilization and to improve the quality of medical services via a multidisciplinary care approach among orthopedic surgeons, rheumatologists and physiatrists. Three centers (Chungnam, Chonnam and Jeju) opened in 2013, one (Dae gu Catholic) in 2014 and one (Gyeongsang) in 2016.

The 00 regional rheumatoid and degenerative arthritis center opened on 25 September 2013 and applied a critical pathway incorporating intensive rehabilitation therapy after TKA. As the coverage of NHIs and HIRAs focused on TKA only in Korea, studies are very limited for post-TKA rehabilitation therapy.

Therefore, the objectives of this study were to analyze the demographic, clinical and socioeconomic characteristics of patients who underwent TKA and to differentiate the factors affecting participation in inpatient-intensive rehabilitation programs after TKA as prerequisites to establish a qualified integrated care system after TKA as a role of regional rheumatoid and degenerative arthritis centers.

\section{Materials And Methods}

\section{Participants}

This retrospective cohort study included 845 patients (735 females and 70 males; average age, $72.0 \pm 5.8$ years) diagnosed with primary OA of the knee who underwent elective unilateral primary TKA at the Department of Orthopedic Surgery in oo National University Hospital between January 2013 and June 2016.

The inclusion criteria consisted of the ability to walk independently with or without an ambulatory aid. The exclusion criteria were as follows: 1) previous neurological or orthopedic disease disturbing ambulation, such as orthopedic injury or previous joint surgery in the lower extremities and unstable cardiorespiratory disease; 2 ) bilateral TKA; 3 ) revision TKA; 4) TKA surgery at another hospital; and 5) combined severe medical complications.

\section{Demographic and clinical data}

Demographic characteristics, including age, sex, weight, height and body mass index (BMI), were calculated as the weight $(\mathrm{kg})$ divided by the height $\left(\mathrm{m}^{2}\right)$. Individuals aged 65 years or older and 75 years or older were classified as elderly and very elderly, respectively, and obesity was defined by the modified Asia-Pacific criteria (BMI $\geq 25.0 \mathrm{~kg} / \mathrm{m}^{2}$ ). [6] The presence of comorbidities such as hypertension (HTN) and diabetes mellitus (DM) was reviewed.

Patients were asked to mark the level of knee pain using a visual analogue scale (VAS) preoperatively. The scale consisted of a $10 \mathrm{~cm}$-long horizontal line ranging from 0 (worst, totally unsatisfied) to 10 (best, 
completely satisfied) points with facial expressions above the line.[7] The severity of knee osteoarthritis was classified in anterior posterior (AP) radiographs using Kellgrene-Lawrence (K-L) grade, which was described as follows:[8] 1) grade 1, doubtful narrowing of the joint space with possible osteophyte formation and 2) grade 2, possible narrowing of the joint space with definite osteophyte formation. 3) grade 3, definite narrowing of joint space, moderate osteophyte formation, some sclerosis, and possible deformity of bony ends; 4) grade 4, large osteophyte formation, severe narrowing of the joint space with marked sclerosis, and definite deformity of bone ends. Comorbidities including hypertension and diabetes that were diagnosed by a physician were also collected. Patients discharged to home were allocated to the TKA-only group, and patients discharged or transferred to the Department of Rehabilitation for intensive rehabilitation programs were assigned to the TKA + rehab group.

The intensive rehabilitation program consisted of progressive resistance exercises (including leg press, leg press, leg extension, leg curl, hip abduction, and hip adduction) using air resistance machines (HUR Co., Kokkola, Finland) and progressive gait training using a lower-body positive pressure treadmill (Alter-G Inc., Fremont, CA, USA) and aerobic exercise using a stationary ergometer.[9] The parameters were also compared before and after the establishment of the center (BEC vs AEC).

\section{Socioeconomic characteristics}

The locations of residence were classified using addresses according to current (Jeju and Seogwipo) and previous administrative districts (Jeju City, Seogwipo City, North Jeju County, South Jeju County). We also investigated whether they lived in urban areas such as Jeju City and Seogwipo City and whether they lived in Jeju City, which has an oo regional rheumatoid and degenerative arthritis center.

The date of admission, date of discharge, length of hospital stay (LOS), in-hospital complications, medical insurance status (National Health Insurance; $\mathrm{NHI}$, Medicaid) and education level were also retrieved.

Education level was categorized depending on the highest diploma that the patient acquired as follows: no formal education, primary education (elementary diploma), secondary education (middle or high school or 2-year college diploma) and finally higher education (university or graduate school diploma). [10]

\section{The classification of occupation}

We also evaluated the job that the patient had for the longest period according to the Korean Standard Classification of Occupations.[11] These occupations were categorized into three groups depending on their degree of physical work: nonmanual workers (managers, professionals and related workers, and clerks), service or sales workers, and manual workers (skilled agricultural, forestry, fishery, craft, and related trades workers, equipment, machine operating and assembling workers, and elementary workers). [12]

\section{Statistical analysis}


For statistical analysis, standard statistical software (SPSS version 20.0 for Windows, SPSS, Inc., Chicago, IL, USA) was used. All descriptive statistics were used, and the data are presented as the mean \pm standard deviation (SD). Nominal and categorical variables were analyzed by $\chi^{2}$ tests. Baseline demographic and clinical characteristics were compared between the TKA-only and TKA + rehabilitation groups and between the BEC and AEC groups (before and after the establishment of the center) using independent sample t-tests for continuous data. A p-value $<0.05$ was considered significant.

\section{Results}

A total of 166 patients were enrolled between January and September 2013, and 679 patients were enrolled from October 2013 to June 2016. The annual numbers of primary TKAs were 227, 225 and 258 in 2013, 2014 and 2015, respectively, and the total number of primary TKAs was 135 during 6 months in 2016. There were significant annual differences in the proportions of manual workers and males and the prevalence of obesity, especially in 2015 (Table 1). 
Table 1

Comparison of general, clinical and socioeconomic characteristics between 2013 and 2015

\begin{tabular}{|c|c|c|c|c|}
\hline Variables & 2013 & 2014 & 2015 & $p$ value \\
\hline Numbers & 227 & 225 & 258 & \\
\hline Age & $71.7 \pm 5.9$ & $71.3 \pm 6.2$ & $72.7 \pm 5.4$ & 0.24 \\
\hline$\leq 59$ & $5(2.2)$ & $6(2.7)$ & $4(1.6)$ & \multirow[t]{4}{*}{0.094} \\
\hline $60-69$ & $76(33.5)$ & 79 (35.1) & $61(23.3)$ & \\
\hline $70-79$ & $126(55.5)$ & $125(55.6)$ & $170(65.9)$ & \\
\hline$\geq 80$ & $20(8.8)$ & $15(6.7)$ & $23(8.9)$ & \\
\hline Elderly ( $\geq 65$ ) & $204(89.9)$ & $200(88.9)$ & $239(92.6)$ & 0.339 \\
\hline Very elderly $(\geq 80$ ) & $20(8.8)$ & $15(6.7)$ & $23(8.9)$ & 0.609 \\
\hline Sex (female: male) & 206 (90.7): 21 (9.3) & $\begin{array}{l}201 \text { (89.3): } 24 \\
(10.7)\end{array}$ & 212 (82.2): 46 (17.8) & $0.009 * *$ \\
\hline Op site (Right) & $93(41.0)$ & $92(40.9)$ & $119(46.1)$ & \\
\hline BMI & $26.8 \pm 3.2$ & $26.1 \pm 3.5$ & $26.3 \pm 3.6$ & 0.076 \\
\hline Weight & $62.2 \pm 9.3$ & $61.7 \pm 9.4$ & $62.7 \pm 10.5$ & 0.546 \\
\hline Obesity & $165(72.7)$ & $130(57.8)$ & $154(59.7)$ & $0.002^{* *}$ \\
\hline LOS & $16.7 \pm 2.2$ & $16.8 \pm 3.5$ & $16.3 \pm 1.5$ & 0.08 \\
\hline VAS & $5.7 \pm 0.7$ & $5.8 \pm 0.4$ & $5.8 \pm 0.5$ & 0.052 \\
\hline \multicolumn{5}{|l|}{$\mathrm{K}-\mathrm{L}$ grade } \\
\hline $3 / 4$ & $\begin{array}{l}75(33.0) / 152 \\
(67.0)\end{array}$ & $\begin{array}{l}59(26.2) / 166 \\
(73.8)\end{array}$ & $63(24.4) / 195(75.6)$ & 0.088 \\
\hline \multicolumn{5}{|l|}{ Education } \\
\hline $\begin{array}{l}\text { No formal } \\
\text { education }\end{array}$ & $31(13.7)$ & $28(12.4)$ & $12(12.4)$ & $0.001^{* *}$ \\
\hline \multicolumn{5}{|l|}{ Occupation } \\
\hline Manual work & $16(7.0)$ & $34(15.1)$ & $133(51.6)$ & $<0.001^{\star *}$ \\
\hline
\end{tabular}

Values are mean \pm standard deviation or numbers (\%)

Op, operation; BMI, body mass index; LOS, length of stay; VAS, visual analogue scale; K-L, KellgreneLawrence; $\mathrm{NHI}$, national health insurance 


\begin{tabular}{|c|c|c|c|c|}
\hline Variables & 2013 & 2014 & 2015 & $\mathrm{p}$ value \\
\hline Urban: Country & $\begin{array}{l}137(60.4): 90 \\
(39.6)\end{array}$ & $\begin{array}{l}132(58.7): 93 \\
(41.3)\end{array}$ & $\begin{array}{l}152(58.9): 106 \\
(41.1)\end{array}$ & 0.924 \\
\hline \multicolumn{5}{|c|}{ Location of residence (Current administrative districts) } \\
\hline Jeju: Seogwipo & $\begin{array}{l}149(65.6): 78 \\
(34.4)\end{array}$ & $\begin{array}{l}148(65.8): 77 \\
(34.2)\end{array}$ & 174 (67.4): 84 (32.6) & 0.895 \\
\hline \multicolumn{5}{|c|}{ Formal administrative districts } \\
\hline Jeju city & $111(48.9)$ & $104(46.2)$ & $122(47.3)$ & 0.848 \\
\hline \multicolumn{5}{|c|}{ Medical insurance } \\
\hline NHI: Medicaid & 209 (92.1): $18(7.9)$ & 215 (95.6): $10(4.4)$ & 249 (96.5): 9 (3.5) & 0.074 \\
\hline \multicolumn{5}{|c|}{ Values are mean \pm standard deviation or numbers (\%) } \\
\hline
\end{tabular}

Only $3 \%$ of the patients were transferred or admitted to the Department of Rehabilitation in the BEC group, whereas $59.2 \%$ agreed with intensive post-TKA rehabilitation in the AEC group. The BEC group showed a higher mean BMl and prevalence of obesity but a lower proportion of patients with K-L grade $4(27.1 \pm 3.2$ $\left.\mathrm{kg} / \mathrm{m}^{2}, 65.7 \%\right)$ than the AEC group $\left(26.2 \pm 3.5 \mathrm{~kg} / \mathrm{m}^{2}, 75.7 \%\right)$ (Table 2). The distributions of education level were significantly different between BEC and AEC groups and the proportion of the patients who did not have any formal education was higher and the proportion of the manual workers were fewer in BEC group $(14.5 \%, 7.2 \%)$ than in AEC group (7.1\% 33.3\%), but there were no significant differences between $B E C$ and $A E C$ groups in the residence-related factors (Table 3). After EC, 59.2\% participated in intensive post-TKA rehabilitation. The BEC group had significantly higher proportions of patients who lived in Jeju of both former and current administrative districts than the AEC group (Tables 3 ). 
Table 2

General and clinical characteristics in all patients and comparison before and after the establishment of regional rheumatoid and degenerative arthritis center

\begin{tabular}{|c|c|c|c|c|}
\hline Variables & All & BEC & AEC & $\mathrm{p}$ value \\
\hline Numbers & 845 & $166(19.6)$ & $679(80.4)$ & \\
\hline Age & $72.0 \pm 5.8$ & $71.1 \pm 5.8$ & $72.2 \pm 5.7$ & $0.03^{*}$ \\
\hline$\leq 59$ & $16(1.9)$ & $4(2.4)$ & $12(1.8)$ & 0.108 \\
\hline $60-69$ & $258(30.5)$ & $63(38.0)$ & $195(28.7)$ & \\
\hline $70-79$ & $501(69.3)$ & $88(53.0)$ & $413(60.8)$ & \\
\hline$\geq 80$ & $70(8.3)$ & $11(6.6)$ & $59(8.7)$ & \\
\hline Elderly ( $\geq 65$ ) & 769 (91.0) & $147(88.6)$ & $622(91.6)$ & 0.227 \\
\hline $\begin{array}{l}\text { Very elderly ( } \geq \\
80 \text { ) }\end{array}$ & $70(8.3)$ & $59(8.7)$ & $11(6.6)$ & 0.436 \\
\hline Sex (female) & 735 (87.0) & $151(91.0)$ & $584(86.0)$ & 0.095 \\
\hline Op site (Right) & 361 (42.7) & $73(44.0)$ & $288(42.4)$ & 0.727 \\
\hline BMI & $26.4 \pm 3.4$ & $27.1 \pm 3.2$ & $26.2 \pm 3.5$ & $0.003^{* \star}$ \\
\hline Weight & $62.1 \pm 9.7$ & $62.8 \pm 8.9$ & $62.0 \pm 9.9$ & 0.323 \\
\hline Obesity & $528(62.5)$ & $124(74.7)$ & $404(59.5)$ & $\begin{array}{l}< \\
0.001^{* *}\end{array}$ \\
\hline LOS & $16.6 \pm 2.4$ & $16.7 \pm 2.3$ & $16.5 \pm 2.5$ & 0.371 \\
\hline Rehabilitation & $407(48.2)$ & $5(3.0)$ & $402(59.2)$ & $\begin{array}{l}< \\
0.001^{* *}\end{array}$ \\
\hline VAS & $5.8 \pm 0.5$ & $5.7 \pm 0.8$ & $5.8 \pm 0.4$ & 0.094 \\
\hline \multicolumn{5}{|l|}{$\mathrm{K}-\mathrm{L}$ grade } \\
\hline $3 / 4$ & $\begin{array}{l}222(26.3) / 623 \\
(73.7)\end{array}$ & $\begin{array}{l}57(34.3) / 109 \\
(65.7)\end{array}$ & $\begin{array}{l}165(24.3) / 514 \\
(75.7)\end{array}$ & $0.01^{*}$ \\
\hline \multicolumn{5}{|c|}{ Underlying diseases } \\
\hline HTN & $564(66.7)$ & $121(72.9)$ & $443(65.2)$ & 0.066 \\
\hline DM & $174(20.6)$ & $34(20.5)$ & $140(20.6)$ & 1 \\
\hline \multicolumn{5}{|c|}{ Values are the mean \pm standard deviation or numbers $(\%),{ }^{*} p<0.05,{ }^{* *} p<0.01$} \\
\hline $\begin{array}{l}\text { EC, the establis } \\
\text { after EC; Op, op } \\
\text { Kellgrene-Lawr }\end{array}$ & $\begin{array}{l}\text { th of regional rhe } \\
\text { on; BMl, body ma } \\
\text { HTN, hypertensic }\end{array}$ & $\begin{array}{l}\text { and degenerati } \\
\text { x; LOS, length of } \\
\text { diabetes mellitu }\end{array}$ & $\begin{array}{l}\text { ritis center; BEC, } \\
\text { AS, visual analog }\end{array}$ & $\begin{array}{l}C ; A E C \\
\text { e; } K-L\end{array}$ \\
\hline
\end{tabular}


Table 3

Socioeconomic characteristics of all patients and comparisons before and after the establishment of the regional rheumatoid and degenerative arthritis center

\begin{tabular}{|c|c|c|c|c|}
\hline Variables & All & BEC & AEC & $\mathrm{p}$ value \\
\hline Education & & & & $0.001^{\star \star}$ \\
\hline $\begin{array}{l}\text { No formal } \\
\text { education }\end{array}$ & $72(8.5)$ & $24(14.5)$ & $48(7.1)$ & $0.005^{\star \star}$ \\
\hline Primary education & $260(30.8)$ & $62(37.3)$ & $198(29.2)$ & \\
\hline $\begin{array}{l}\text { Secondary } \\
\text { education }\end{array}$ & $490(58.0)$ & $76(45.8)$ & $414(61.0)$ & \\
\hline Higher education & $23(2.7)$ & $4(2.4)$ & $19(2.8)$ & \\
\hline \multicolumn{5}{|l|}{ Occupation } \\
\hline Manual work & $238(28.2)$ & $12(7.2)$ & $226(33.3)$ & $\begin{array}{l}< \\
0.001^{* *}\end{array}$ \\
\hline \multicolumn{5}{|l|}{ Urban residence } \\
\hline Urban: Country & $\begin{array}{l}509(60.2): 336 \\
(39.8)\end{array}$ & $\begin{array}{l}\text { 103(62.0): } 63 \\
(38.0)\end{array}$ & $\begin{array}{l}406(59.8): 273 \\
(40.2)\end{array}$ & 0.658 \\
\hline \multicolumn{5}{|c|}{ Location of residence (Current administrative districts) } \\
\hline Jeju: Seoqwipo & $\begin{array}{l}557 \text { (65.9): } 288 \\
(34.1)\end{array}$ & $\begin{array}{l}105(63.3): 61 \\
(36.7)\end{array}$ & $\begin{array}{l}251(57.3): 187 \\
(42.7)\end{array}$ & 0.465 \\
\hline \multicolumn{5}{|c|}{ Formal administrative districts } \\
\hline Jeju city & $402(47.6)$ & $80(48.2)$ & $322(47.4)$ & 0.863 \\
\hline \multicolumn{5}{|l|}{ Medical insurance } \\
\hline NHI: Medicaid & 799 (94.6): $46(5.4)$ & $\begin{array}{l}152(91.6): 14 \\
(8.4)\end{array}$ & 647 (95.3): 32 (4.7) & 0.083 \\
\hline \multicolumn{5}{|c|}{ Values are the mean \pm standard deviation or numbers (\%), ${ }^{\star} p<0.05,{ }^{* \star} p<0.01$} \\
\hline
\end{tabular}

There was no significant different between rehabilitation group and home discharge group in general and clinical characteristics (Table 4) and the proportion of residence of Jeju city in both formal and current administrative districts was significantly high and the education level was significantly different between two groups. (Table 5) 
Table 4

General and clinical characteristics of patients after the establishment of regional rheumatoid and degenerative arthritis centers and comparisons between the home discharge and rehabilitation groups

\begin{tabular}{|c|c|c|c|}
\hline Variables & TKA + Rehab & TKA only & $\mathrm{p}$ value \\
\hline Numbers & $402(59.2)$ & $277(40.8)$ & \\
\hline Age & $72.1 \pm 5.9$ & $72.2 \pm 5.6$ & 0.33 \\
\hline$\leq 59$ & $7(1.7)$ & $4(2.5)$ & 0.436 \\
\hline $60-69$ & $121(30.1)$ & $62(38.5)$ & \\
\hline $70-79$ & $235(58.5)$ & $85(52.8)$ & \\
\hline$\geq 80$ & $39(9.7)$ & $10(6.2)$ & \\
\hline Elderly ( $\geq 65$ ) & $366(91.0)$ & $256(92.4)$ & 0.575 \\
\hline Very elderly ( $\geq 80$ ) & $39(9.7)$ & $20(7.2)$ & 0.271 \\
\hline Sex & $343(85.3)$ & $241(87.0)$ & 0.575 \\
\hline Op site (Right) & $173(43.0)$ & $115(41.5)$ & 0.752 \\
\hline BMI & $26.0 \pm 3.4$ & $26.4 \pm 3.5$ & 0.204 \\
\hline Weight & $61.9 \pm 9.7$ & $62.4 \pm 9.8$ & 0.441 \\
\hline Obesity & $227(56.5)$ & $177(63.9)$ & 0.601 \\
\hline LOS & $16.5 \pm 2.7$ & $16.5 \pm 2.1$ & 0.908 \\
\hline VAS & $5.8 \pm 0.4$ & $5.8 \pm 0.5$ & 0.294 \\
\hline \multicolumn{4}{|l|}{ K-L grade } \\
\hline $3 / 4$ & $110(27.0) / 297(73.0)$ & $112(25.6) / 326(74.4)$ & 0.64 \\
\hline \multicolumn{4}{|l|}{ Underlying diseases } \\
\hline HTN & $266(66.2)$ & 177 (63.9) & 0.566 \\
\hline DM & $82(20.4)$ & $28(20.9)$ & 1 \\
\hline \multicolumn{4}{|c|}{ Values are the mean \pm standard deviation or numbers $(\%),{ }^{*} p<0.05,{ }^{*} p<0.01$} \\
\hline $\begin{array}{l}\text { Op, operation; BMI, } \\
\text { Lawrence; HTN, hyp }\end{array}$ & $\begin{array}{l}\text { s index; LOS, length of } \\
\text { DM, diabetes mellitus }\end{array}$ & , visual analogue sc & Igrene- \\
\hline
\end{tabular}


Table 5

Socioeconomic characteristics of patients after the establishment of regional rheumatoid and degenerative arthritis centers and comparisons between the home discharge and rehabilitation groups

\begin{tabular}{|c|c|c|c|}
\hline Variables & TKA + Rehab & TKA only & p value \\
\hline Education level & & & $0.034^{*}$ \\
\hline No formal education & $26(6.5)$ & $22(7.9)$ & 0.543 \\
\hline Primary education & $133(33.1)$ & $65(23.5)$ & $0.035^{\star}$ \\
\hline Secondary education & $230(57.2)$ & $184(66.4)$ & $0.035^{\star}$ \\
\hline Higher education & $13(3.2)$ & $6(2.2)$ & 0.483 \\
\hline \multicolumn{4}{|l|}{ Occupation } \\
\hline Manual work & $140(34.8)$ & $86(31.0)$ & 0.321 \\
\hline \multicolumn{4}{|c|}{ Urban residence (Jeju city and Seogwipo city) } \\
\hline Urban: Country & 242 (60.2): $160(39.8)$ & 164 (59.2): $113(40.8)$ & 1 \\
\hline \multicolumn{4}{|c|}{ Location of residence (Current administrative districts) } \\
\hline Jeju: Seogwipo & 303 (75.4): 99 (24.6) & 149 (53.8): 128 (46.2) & $<0.001^{* *}$ \\
\hline \multicolumn{4}{|c|}{ Formal administrative districts } \\
\hline Jeju city & $213(53.0)$ & $109(39.4)$ & $0.001^{\star \star}$ \\
\hline \multicolumn{4}{|l|}{ Medical insurance } \\
\hline NHI: Medicaid & 385 (94.6): $22(5.4)$ & 414 (94.5): 24 (5.5) & 1 \\
\hline \multicolumn{4}{|c|}{ Values are the mean \pm standard deviation or numbers $(\%),{ }^{*} p<0.05,{ }^{*} p<0.01$} \\
\hline $\mathrm{NHI}$, national health in & urance & & \\
\hline
\end{tabular}

\section{Discussion}

This study confirmed the demographic, clinical and socioeconomic characteristics of patients who underwent TKA, and after the establishment of the center, the need for an inpatient-intensive rehabilitation program after TKA increased from $3-59.2 \%$ in 00 regional rheumatoid and degenerative arthritis centers. These trends of increasing male sex and older patients (age $\geq 70$ ) were similar to those of a study using the HIRA Korean database, which reported procedure rates of 155.5 (2013), 155.8 (2014) and 173.3 (2015) per 100,000 people.[3] It also reported that the proportion of patients more than 70 years old increased markedly from $48.1 \%$ (2010) to $61 \%$ (2018)[3]. In this study, the mean age of all participants $(72.0 \pm 5.8)$ was in the early 70 s, which was recommended as an optimal age for TKA that could achieve the maximal passive range of motion (PROM) without increasing the revision or mortality 
rates[13]. A total of $60.2 \%$ lived in urban areas, $65.9 \%$ lived in Jeju city of current administrative districts, and $47.6 \%$ lived in Jeju city of formal administrative districts. Manual workers accounted for $28.2 \%$ of all participants, approximately $20 \%$ of Jeju and $33 \%$ of Seogwipo.

Interestingly, the mean duration of LOS was $16.7 \pm 2.2$ days, and it might be prolonged compared with Western countries such as the United States (3.6 \pm 1.7 days)[14] and Denmark ( $3 \pm 3$ days in elective cases, $5 \pm 6$ days in nonelective cases).[15] However, notably, our data were shorter than the average LOS of the HIRA (21.2 days in 2018)

However, the national medical insurance systems worldwide that guarantee universal coverage to treatment usually allowed longer LOS if there were reasonable reasons such as bilateral arthroplasty, intractable pain, gait instability, and other perioperative complications[16] and especially, the national medical insurance systems of Japan supported coverage during much longer LOS (35.1 \pm 1.7 days)[17] and provided comprehensive rehabilitation therapy in long-term care wards for community-based integrated care systems.[18]

A recent large-scale study based on HIRA registries reported a gradual increase in TKA growth in Korea from 2010 to 2018, contrary to the dramatic increase in the growth rate before 2010[3], which might be caused by improved accessibility to the medical system as well as an increase in the geriatric population. [19] They concluded that the demographic characteristics of Korea are quite different and that the revision rates were very low, although primary TKA use was popular and similar to the most developed Western countries. They also insisted that further studies on various demographic variables would be necessary and that Korean policymakers and healthcare providers should prepare for revision burdens and comorbidity care for the elderly and very elderly based on a comprehensive analysis of various patients' demographical and clinical information.[19]

Our data also indicated that the total number of TKAs had been steady or had increased gradually after EC by $114 \%$ between 2014 and 2015, and they showed higher proportions of females and geriatrics and a substantial prevalence of comorbidities such as HTN and DM. Interestingly, the number of males, geriatrics and manual workers increased, which might be affected by the westernization of lifestyle and manual work that prevented rapid osteoarthritis progression. The regional rheumatoid and degenerative arthritis center is an emerging experimental model for managing arthritis, comorbidities and perioperative side effects that integrates medical and surgical treatment with rehabilitation in Korea.

This result was the first study with a detailed review of various characteristics of patients undergoing TKA in the regional rheumatoid and degenerative arthritis center, and it was comparable to represent the general population of Korean TKA use. Notably, the need for post-TKA rehabilitation was very high, but the main factor differentiating participation in rehabilitation was the location of residence despite slightly different distributions of education level between the two groups (Table 5). Thus, establishing regional rheumatoid and degenerative arthritis centers in their residence is appropriate for the integrated care of arthritis in geriatrics. 
On the other hand, the mean duration of LOS in this study was relatively constant regardless of EC and rehabilitation. This might be explained by the fact that the hospital preferred readmission after discharge rather than transfer to the inpatient rehabilitation ward because the Korean HIRA cut or reduced the Medicare payment if the LOS was more than 15 days. Considering the average LOS ( 21 days) and lack of long-term care wards for TKA in Korea, policy support would be necessary to ensure sufficient days of hospitalization after TKA and to build incentive programs for early rehabilitation and a qualified integrated care system.

This study had some limitations. First, it was a retrospective cohort study, and the available demographical and clinical data were very limited, especially in the TKA-only group. Second, it was a cross-sectional analysis without follow-up. Thus, we could not analyze the effect of preoperative status or monitor functional changes between admission and discharge. Third, we excluded revision procedures and could compare primary TKA with revision. Third, the practice patterns might differ according to the facilities and region, which might affect LOS, and participation in rehabilitation might differ according to the facilities. Finally, this study has a limitation in exploring the causative and longitudinal relationship of rehabilitation therapy with functional outcome.

In conclusion, this study revealed that the demographical and clinical characteristics of patients who underwent primary TKA in an 00 regional rheumatoid and degenerative arthritis center showed a predominance of females and geriatrics and a high prevalence of comorbidities and obesity. Additionally, the only factor differentiating participation in intensive rehabilitation was the location of residence. Thus, the regional rheumatoid and degenerative arthritis center was appropriate to meet the high need for participating in intensive rehabilitation after TKA and for the qualified integrated post-TKA care system. Furthermore, policy support should ensure adequate hospital stay after TKA, build incentive programs for early rehabilitation and qualified integrated care systems and prepare for the increased burden of revision, and future longitudinal studies should be conducted to assess the long-term effect of the integrated post-TKA rehabilitation program on functional outcomes and patient survivorship free from revision.

\section{Abbreviations}

AEC: after the establishment of the center;AP: anterior posterior; BEC: before the establishment of the center; BMI: body mass index; DM: diabetes mellitus; HIRA: Health Insurance Review and Assessment Service; HTN: hypertension; LOS: length of hospital stay; NHI: National Health Insurance; OA: osteoarthritis; OOP: pay out-of-pocket; PROM: passive range of motion; TKA: total knee arthroplasty; VAS: visual analogue scale

\section{Declarations}

\section{Acknowledgments}


Not applicable.

\section{Author contributions}

E.Y.H. and S.H.I. had full access to all of the data in the study and takes responsibility for the integrity of the data and the accuracy of the data analysis ant contributed to the study design, data analysis and interpretation, and the writing of the manuscript

S.R.K. contributed substantially to patient enrollment, data analysis and interpretation, and the writing of the manuscript.

\section{Funding}

This work was supported by a research grant from Jeju National University Hospital in 2016. The funders had no role in study design, data collection and analysis, decision to publish or preparation of the manuscript.

\section{Availability of data and materials}

The datasets used and/or analyzed during the current study are available from the first and corresponding authors on reasonable request.

\section{Ethics approval and consent to participate}

Given the retrospective study design, informed consent from patients in this research was waived by the institutional review board of 00 National University Hospital, and the study protocol was reviewed and approved by the Institutional Review Board of OO National University Hospital (0000-IRB 2019-10-004).

\section{Consent for publication}

Not applicable.

\section{Competing interests}

The authors declare that they have no conflicts of interests.

\section{References}

1. Salaffi F, Di Carlo M, Carotti M, Farah S, Giovagnoni AJAC, Research E: Frailty prevalence according to the Survey of Health, Ageing and Retirement in Europe-Frailty Instrument (SHARE-FI) definition, and its variables associated, in patients with symptomatic knee osteoarthritis: findings from a crosssectional study. 2020:1-9.

2. Lavernia CJ, Guzman JF, Gachupin-Garcia AJCo, research r: Cost effectiveness and quality of life in knee arthroplasty. 1997, 345(1):134-139. 
3. Kim TW, Kang SB, Chang CB, Moon SY, Lee YK, Koo KH: Current Trends and Projected Burden of Primary and Revision Total Knee Arthroplasty in Korea Between 2010 and 2030. The Journal of arthroplasty 2021, 36(1):93-101.

4. Korea S: Number and costs of surgical procedures in Korea 2006-2018; 2019. In.

5. Lee W-Y, Shaw IJljoer, health $p$ : The impact of out-of-pocket payments on health care inequity: the case of national health insurance in South Korea. 2014, 11(7):7304-7318.

6. Organization WH: The Asia-Pacific perspective: redefining obesity and its treatment. 2000.

7. Carlsson AMJP: Assessment of chronic pain. I. Aspects of the reliability and validity of the visual analogue scale. 1983, 16(1):87-101.

8. Kellgren J, Lawrence JJAotrd: Radiological assessment of osteo-arthrosis. 1957, 16(4):494.

9. Kim JH, Kim BR, Kim SR, Han EY, Nam KW, Lee SY, Kim WBJAoRM: Functional outcomes after critical pathway for inpatient rehabilitation of total knee arthroplasty. 2019, 43(6):650.

10. Shin M, Sohn MK, Lee J, Kim DY, Lee S-G, Shin Y-I, Oh G-J, Lee Y-S, Joo MC, Han EYJS: Effect of cognitive reserve on risk of cognitive impairment and recovery after stroke: the KOSCO study. 2020, 51(1):99-107.

11. Korea S: Korean standard classification of occupations. In.: Statistics Korea Daejeon; 2017.

12. Lee K: The association between occupational categories and grip strength in Korean male workers. International archives of occupational and environmental health 2021.

13. Lee SH, Kim DH, Lee YSJKs, research r: Is there an optimal age for total knee arthroplasty?: A systematic review. 2020, 32(1):1-11.

14. Singh JA, Lu X, Rosenthal GE, Ibrahim S, Cram PJAotrd: Racial disparities in knee and hip total joint arthroplasty: an 18-year analysis of national Medicare data. 2014, 73(12):2107-2115.

15. Husted H, Jensen CM, Solgaard S, Kehlet HJAoo, surgery t: Reduced length of stay following hip and knee arthroplasty in Denmark 2000-2009: from research to implementation. 2012, 132(1):101-104.

16. Ishii Y, Noguchi H, Takeda M, Sato J, Suzuki TJEJoOS, Traumatology: Length of hospital stay with patient-dependent determination in bilateral scheduled staged total knee arthroplasty. 2014, 24(6):961-965.

17. Yasunaga $H$, Tsuchiya $K$, Matsuyama Y, Ohe KJJoOS: Analysis of factors affecting operating time, postoperative complications, and length of stay for total knee arthroplasty: nationwide web-based survey. 2009, 14(1):10.

18. Igarashi A, Yamamoto-Mitani N, Morita K, Matsui H, Lai CK, Yasunaga HJBhsr: Classification of longterm care wards and their functional characteristics: analysis of national hospital data in Japan. 2018, 18(1):1-8.

19. Losina E, Thornhill TS, Rome BN, Wright J, Katz JNJTJoB, volume. JSA: The dramatic increase in total knee replacement utilization rates in the United States cannot be fully explained by growth in population size and the obesity epidemic. 2012, 94(3):201. 